\title{
BULGARIAN RHEUMATOLOGY SOCIETY RECOMMENDATIONS FOR BEHAVIOR DURING AN EPIDEMIC WITH COVID-19
}

\author{
R. Stoilov', V. Boyadzhieva ${ }^{1}$, N. Stoilov ${ }^{1}$, M. Ivanova ${ }^{1}$, A. Batalov ${ }^{2}$, Zl. Kolarov' ${ }^{1}$, S. Monov ${ }^{1}$, I. Sheytanov ${ }^{1}$ \\ ${ }^{1}$ Clinic of Rheumatology, University Hospital „Sv. Iv. Rilski”, Medical University - Sofia \\ ${ }^{2}$ Clinic of Rheumatology, University Hospital "Caspela”, Medical University - Plovdiv
}

The rapid spread of the new coronavirus (SARS-CoV-2) around the world has posed many challenges to rheumatic patients and their physicians. Uncertainty and conflicting information, as well as the characteristics of highly contagious viral infection with a mortality of about $3 \%$, necessitated the adoption of uniform recommendations for behavior during the COVID-19 epidemic. In April 2020, the two main rheumatological organizations: the European League Against Rheumatism (EULAR) and the American College of Rheumatology (ACR) published recommendations for behavior during an epidemic with SARS-CoV-2, as well as an opinion on the use of immunomodulatory or immunosuppressive treatment. In support of these recommendations, the British Society for Rheumatology (BSR) and the Australian Rheumatology Association (ARA) have also adopted algorithms for behavior in COVID-19 infection. Although the recommendations made were accepted with a high level of agreement, their scientific value is scarce. The level of evidence never exceeds that of "expert opinion" and therefore the strength of the recommendations is axiomatically low.

In view of the extraordinary epidemic situation lasting more than 8 months in the Republic of Bulgaria, as well as the pandemic with SARS-CoV-2 worldwide, the Bulgarian Society of Rheumatology (BDR) offers the following recommendations for behavior during an epidemic with COVID-19:

1. Strict observance of the sanitary-hygienic and anti-epidemic measures, ordered by the $\mathrm{NOH}(\mathrm{Na}-$ tional Operational Headquarters) and the respective competent authorities in the country.

2. If a patient has a fever and/or persistent cough, taste or olfactory disturbances, COVID-19 should be tested. If the result is negative, the test is repeated.

3. Consultation with a rheumatologist „face to face", especially for patients on bDMARDS and JAK inhibitors, cannot be postponed for more than 6 months. In the absence of urgency, regular examinations and consultations with a rheumatologist may be temporarily postponed or conducted by telephone.
4. The committees may, at their discretion, issue Protocol $1 \mathrm{C}$ for biological DMARDS and JAK inhibitors for a period of 6 to 12 months only if there is a written consultation from the treating rheumatologist with an opinion on the continuation, suspension or change of treatment.

5. Patients with rheumatic diseases who are not suspected or have no proven COVID-19 infection should not discontinue treatment or change the dose of conventional synthetic DMARDS (csDMARDS), biological DMARDS (bDMARDS), JAK-inhibitors, glucocorticoids, NSAIDs and antiosteoporotic agents as a preventive measure.

6. Patients with rheumatic diseases, asymptomatic of COVID-19 who have been in contact with a SARS-CoV-2-positive person, should be tested for SARS-CoV-2 as initiated treatment with csDMARD, bDMARD, JAK-inhibitors, glucocorticoids, NSAIDs and antiosteoporotic agents are not discontinued.

7. In case of confirmed COVID-19 infection, csDMARDS, bDMARDS and JAK inhibitors (except chloroquine/ hydroxychloroquine and sulfasalazine) must be stopped. Their intake is restored after recovery and two negative tests.

8. Do not stop treatment with corticosteroids, even in cases of proven active COVID-19 infection.

9. In patients with systemic rheumatic diseases (active lupus, active vasculitis, active systemic sclerosis) treated with cyclophosphamide or glucocorticosteroids, prevention of pneumonia from Pneumocystis jiroveci (PJP) should be considered. This pneumonia can be clinically mistaken for COVID-19 pneumonia also because PJP is an unavoidable condition and coexistence of the two pneumonias can be expected.

10. If a patient with rheumatic disease requires outpatient or inpatient treatment, patients and members of the rheumatology team should follow national and local guidelines for infection prevention and control, including the use of personal protective equipment.

11. Patients should be informed of the appropriate vaccinations with influenza and pneumococcal vaccine. Follow the instructions according to the $\mathrm{Na}-$ tional Immunization Calendar and the EULAR recommendations. 
12. Pulmonologists, infectious disease specialists, internists and other specialists have the main responsibility for the diagnosis and treatment of COVID-19 in patients with rheumatic diseases, depending on local circumstances and the orders of the Minister of Health. Rheumatologists are the leading experts in the immunosuppressive treatment of their patients and should be involved in the decision to maintain or discontinue it.

13. Prenatal care is essential for maintaining a healthy pregnancy, which is why it is recommended that pregnant women with rheumatic diseases go to a gynecological clinic if invited.

14. If a pregnant woman or a family member has symptoms of COVID-19, it is advisable to contact the supervising obstetrician-gynecologist to arrange the correct place and time for the visit. A routine visit to an obstetric clinic or outpatient clinic is not recommended.

15. The choice of time of birth should be individualized depending on the gestational week, the condition of the mother and fetus.

16. The delivery should be performed according to the obstetric indications. Whenever possible, per vias naturales should be preferred with possible instrumental support to avoid maternal exhaustion and unnecessary surgical complications in an already ill patient.

17. Septic shock, acute organ failure or fetal distress require urgent Caesarean section or premature termination of pregnancy.

18. Newborns from SARS-CoV-2-positive mothers should be isolated for at least 14 days or until viral secretion is eliminated, during which time breast-feeding is not recommended.

\section{Библиография / References}

1. ACR guidance for patients during the Covid-19 outbreak. https:// www.rheum atolo gy.org/annou nceme nts. Accessed 29 Mar.2020.

2. Askanase AD, Khalili L, Buyon JP. Thoughts on COVID-19 and autoimmune diseases. Lupus Sci Med. $2020 \mathrm{https}: / /$ doi. org/10.1136/lupus-2020-000396

3. Australian Rheumatology Association guidance for patients during the Covid-19 outbreak. https ://arthritis australia.com. au/advice-regarding-coronavirus-covid-19-from-the-australian-rheumatology-association/ Accessed 19 Mar 2020.

4. Boyadzhieva, VV., Stoilov, NR, Stoilov, RM. Coronavirus disease 2019 (COVID-19) during pregnancy in patients with rheumatic diseases. Rheumatol Int 2020;40, 1753-1762.

5. BSR guidance for patients during the Covid-19 outbreak. https :// www.rheum atolo gy.org.uk/News-Polic y/Details/Covid 19 Coronavirus-update-members Accessed 29 Mar 2020.

6. Bin Chao. Chinese guidelines of diagnosis and treatment of COVID-19 (7th version). https ://www.sforl .org/wp-conte nt/uploads/2020/03/WUHAN-Exper ience.pdf Accessed 18 Mar 2020.

7. Coronavirus (COVID-19) infection and pregnancy. Version 7 (2020) Guidance for healthcare professionals on coronavirus (COVID-19) infection in pregnancy, published by the RCOG,
Royal College of Midwives, Royal College of Paediatrics and Child Health, Public Health England and Health Protection Scotland. https ://www.rcog.org.uk/globa lasse ts/docum ents/guide lines /2020-04-09-coron aviru s-covid -19-infec tion-in-pregnancy.pdf Accessed: 9 Apr 2020.

8. EULAR guidance for patients during the Covid-19 outbreak. https ://www.eular .org/eular guida nce_for_patie nts_covid 19_outbr eak.cfm Accessed 19 Mar 2020

9. Favre G, Pomar L, Qi X et al. Guidelines for pregnant women with suspected SARSCoV - infection. Lancet Infect Dis. 2020;(20)30157-2.

10. Favalli E, Biggioggero M, Maioli G et al. Baricitinib for COVID-19: a suitable treatment? Lancet Infect Dis. 2020. https ://doi. org/10.1016/S1473-3099(20)30262-0

11. Huang C, Wang Y, Li X et al. Clinical features of patients infected with 2019 novel coronavirus in Wuhan China. Lancet 2020;395:497-506.

12. Liu D, Li L, Wu X et al. Pregnancy and Perinatal Outcomes of Women with COVID-19 Pneumonia: A Preliminary Analysis. Available at SSRN: 2020. https ://ssrn.com/abstr act=3548758.

13. Martinez-Portilla RJ, Gonce A, Hawkins - Villarreal A, Figueras F. A Spanish - translated clinical algorithm for management of suspected SARS-CoV-2 infection in pregnant women. Lancet Infect Dis. 2020. https ://doi.org/10.1016/S1473-3099(20)30285-1

14. Mathian A, Mahevas M, Rohmer J et al. Clinical course of coronavirus disease 2019 (COVID-19) in a series of 17 patients with systemic lupus erythematosus under long-term treatment with hydroxychloroquine. Ann Rheum Dis. 2020. https ://doi. org/10.1136/annrh eumdi s-2020-21756 6

15. Meselson M (2020) Droplets and aerosols in the transmission of SARS-CoV-2. N Engl J Med. https ://doi.org/10.1056/NEJMc20093 16

16. Misra DP, Agarwal V, Gasparyan AY, Zimba O. Rheumatologists' perspective on coronavirus disease 19 (COVID-19) and potential therapeutic targets. Clin Rheumatol 2020;39:2055-2062.

17. National Psoriasis Foundation Medical Board COVID-19 Recommendations for patients with psoriatic disease. https ://www.psoriasis.org/advan ce/coron aviru s Accessed 10 Apr 2020.

18. Practical guidance for the prevention of thrombosis and management of coagulopathy and disseminated intravascular coagulation of patients infected with COVID-19 (2020) https ://thrombosis uk.org/covid-19-throm bosis.php Accessed 07 Apr 2020.

19. Stebbing J, Phelan A, Griffin I et al. COVID-19: combining antiviral and anti-inflammatory treatments. Lancet Infect Dis 2020;20:400-402.

20. The COVID-19 Global Rheumatology Alliance. https ://rheumcovid.org

21. The COVID-19 Global Rheumatology Alliance Global Registry. https://mailc hi.mp/a6dc8 06714 81/just-launc hed-the-covid-19globa I-rheum atolo gy-regis try-48107 62

22. Tisoncik JR, Korth MJ, Simmons CP et al. Into the eye of the cytokine storm. Microbiol Mol Biology Rev Mmbr 2012;76:16-32.

23. World Health Organization. Q\&A on coronaviruses (COVID-19). https ://www.who.int/news-room/q-a-detai l/q coron aviruses. Accessed: 17 Apr 2020.

24. Wu Z, McCoogan JM. Characteristics of and important lessons from the coronavirus disease 2019 (COVID-19) outbreak in China: summary of a report of 72,314 cases from the Chinese Center for Disease Control and Prevention. JAMA 2020;323(13):1239-1242.

25. Yongwen L, Kai $Y$ (2020) Management of pregnant women infected with COVID-19. Lancet Infect Dis. https ://doi.org/10.1016/ S1473-3099(20)30191-2

26. Yudin MH, Steele DM, Sgro MD et al. Severe acute respiratory syndrome in pregnancy. Obstet Gynecol 2005;105:124-127.

27. Zhang W, Du R-H, Li B et al. Molecular and serological investigation of 2019-nCoV infected patients: implication of multiple shedding routes. Emerg Microbes Infect 2020;9:386-389. 